\title{
An Update on the Oceanic Precipitation Rate and Its Zonal Distribution in Light of Advanced Observations from Space
}

\author{
Ali BEHRANGi AND GRAEME STEPHENS \\ Jet Propulsion Laboratory, California Institute of Technology, Pasadena, California \\ ROBERT F. ADLER \\ Earth System Science Interdisciplinary Center, University of Maryland, College Park, College Park, Maryland \\ GEORGE J. HUFFMAN \\ NASA Goddard Space Flight Center, Greenbelt, Maryland \\ BJORN LAMBRIGTSEN AND MATTHEW LEBSOCK \\ Jet Propulsion Laboratory, California Institute of Technology, Pasadena, California
}

(Manuscript received 30 October 2013, in final form 31 January 2014)

\begin{abstract}
This study contributes to the estimation of the global mean and zonal distribution of oceanic precipitation rate using complementary information from advanced precipitation measuring sensors and provides an independent reference to assess current precipitation products. Precipitation estimates from the Tropical Rainfall Measuring Mission (TRMM) precipitation radar (PR) and CloudSat cloud profiling radar (CPR) were merged, as the two complementary sensors yield an unprecedented range of sensitivity to quantify rainfall from drizzle through the most intense rates. At higher latitudes, where TRMM PR does not exist, precipitation estimates from Aqua's Advanced Microwave Scanning Radiometer for Earth Observing System (AMSR-E) complemented CloudSat CPR to capture intense precipitation rates. The high sensitivity of CPR allows estimation of snow rate, an important type of precipitation at high latitudes, not directly observed in current merged precipitation products. Using the merged precipitation estimate from the CloudSat, TRMM, and Aqua platforms (this estimate is abbreviated to MCTA), the authors' estimate for 3-yr (2007-09) nearglobal $\left(80^{\circ} \mathrm{S}-80^{\circ} \mathrm{N}\right)$ oceanic mean precipitation rate is $\sim 2.94 \mathrm{~mm} \mathrm{day}^{-1}$. This new estimate of mean global ocean precipitation is about $9 \%$ higher than that of the corresponding Climate Prediction Center (CPC) Merged Analysis of Precipitation (CMAP) value $\left(2.68 \mathrm{~mm} \mathrm{day}^{-1}\right)$ and about $4 \%$ higher than that of the Global Precipitation Climatology Project (GPCP; $2.82 \mathrm{~mm} \mathrm{day}^{-1}$ ). Furthermore, MCTA suggests distinct differences in the zonal distribution of precipitation rate from that depicted in GPCP and CMAP, especially in the Southern Hemisphere.
\end{abstract}

\section{Introduction}

Precipitation is essential for life and plays an important role in the energy balance of the planet (Kiehl and Trenberth 1997; Trenberth et al. 2009; Stephens et al. 2012; Wong et al. 2014). Quantifying the amount and distribution of precipitation is critical for understanding

Corresponding author address: Ali Behrangi, Jet Propulsion Laboratory, California Institute of Technology, 4800 Oak Grove Drive, MS 233-304, Pasadena, CA 91109.

E-mail: ali.behrangi@jpl.nasa.gov the current state of Earth's climate and future changes (Stephens et al. 2012; Trenberth et al. 2007). Latent heat flux is commonly inferred from precipitation measurement; hence any long-term change in precipitation amount implies a change in evaporation to sustain their balance (Stephens et al. 2012). Current climate models contain serious biases in the modeling and prediction of precipitation (Stephens et al. 2010), but it is also important to realize that our current precipitation observations are not perfect (Behrangi et al. 2012). Recognizing the importance of accurate estimation of precipitation climatology, the Global Precipitation Climatology Project

DOI: 10.1175/JCLI-D-13-00679.1

(C) 2014 American Meteorological Society 
(GPCP) was formed as a community-based analysis of global precipitation under the auspices of the World Climate Research Program (WCRP) from 1979 to the present (Adler et al. 2003; Huffman et al. 2009) and the dataset has been widely used by the research community. Currently, observational climatology of precipitation is largely based on GPCP and the Climate Prediction Center (CPC) Merged Analysis of Precipitation (CMAP; Xie and Arkin 1997) products.

A major goal of these products is to provide a consistent long time series of monthly and finer time resolution precipitation analyses on a global scale. GPCP products are available from the primary monthly product to pentad (Xie et al. 2003) and daily (Huffman et al. 2001) time scales. The global long-term data are obtained by merging rain data from gauges (restricted to over land) and spaceborne sensors, including Special Sensor Microwave Imager and Special Sensor Microwave Imager/Sounder, and geostationary and polarorbiting infrared imagers and sounders. The GPCP merger procedure uses more accurate estimates of precipitation (e.g., gauges over land and passive microwave) to adjust the bias in other estimates (e.g., from infrared imagers and sounders) and then combines the estimates with an inverse error weighting technique. The combination of data from these multiple sensors/ sources remains a challenging task as there are time and space discontinuities in the datasets due to instrumentation and algorithm changes. Another challenge that GPCP faces is high-latitude precipitation estimation, as the current retrieval algorithms that are based on infrared and microwave sensors are not robust enough to retrieve accurate rain and snow rates (Liu 2008; Behrangi et al. 2012). GPCP infers the high-latitude precipitation (including snow) rate using a regression relationship between collocated rain gauge measurements (adjusted for wind loss, including relation to snow) and a few cloud-related parameters (e.g., cloud-top pressure, fractional cloud cover, and cloud-layer relative humidity) obtained from Television Infrared Observation Satellite (TIROS) Operational Vertical Sounder (TOVS) and Atmospheric Infrared Sounder (AIRS) data (Susskind et al. 1997; Adler et al. 2003; Huffman et al. 2009). A recent comparison of high-latitude GPCP precipitation estimates with gauge observations over Finland showed that GPCP produces a reasonable estimate of precipitation over this region, which to a great degree is rooted in the utilization of a few gauges in the product (Bolvin et al. 2009). In fact, just having the gauge climatology is an important step, as shown by the calibrated multisatellite product. Clearly, the challenge is more significant over ocean, as there is almost no surface observation to biasadjust or verify the performance of the product. The empirical estimating techniques developed with coastal and island gauges are then applied over the ocean. Finally, precipitation estimates from several advanced sensors [e.g., the Tropical Rainfall Measuring Mission (TRMM)] have been neglected in the current version of GPCP, in order to maintain a consistent climate record created from relatively homogenous data sources, a concept now known as a climate data record.

CMAP provides gridded global monthly estimate of precipitation using many of the same datasets as GPCP, plus Microwave Sounding Unit (MSU) data. However, the merging of the individual data sources is different from GPCP. Using gauge-based analysis and atoll gauge data, the individual random error is defined for each grid and for each month and the satellite estimates are combined linearly through the maximum likelihood estimation method to reduce the random error. Postprocessing is then carried out to reduce biases by comparing the estimates to the atoll rain gauge data over the tropics and by subjective assumption regarding the bias structure over the extratropics (Xie and Arkin 1997). CMAP implicitly accounts for snowfall using microwave sensors with significant shortcomings for precipitation retrievals at high latitudes.

Arguably, the recent higher-quality precipitation estimates from spaceborne sensors should be used to provide an independent reference or guideline to assess or improve precipitation records such as GPCP and CMAP. The CloudSat Cloud Profiling Radar (CPR) and TRMM Precipitation Radar (PR) are among the recent sensors that can provide unprecedented accuracies and sensitivities to estimate precipitation rates from snow and drizzle all the way to intense rainfall. Berg et al. (2010) showed that the precipitation estimates from the two radars are complementary to construct a merged distribution of rain volume spanning a broad range of rain intensities. Behrangi et al. (2012) constructed a merged distribution of rain volume over ocean between $60^{\circ} \mathrm{S}$ and $60^{\circ} \mathrm{N}$ using TRMM and CloudSat and used the merged distribution as a reference to evaluate the performance of precipitation retrievals from several spaceborne instruments.

The present paper extends the previous work by Behrangi et al. (2012) by 1) extending the study area to almost the entire CloudSat sampled region $\left(80^{\circ} \mathrm{S}-80^{\circ} \mathrm{N}\right)$, 2) including global snow rate from recently developed and modified snow retrieval algorithms, and 3) comparing the amount and distribution of the merged precipitation product with the most recent version of GPCP (version 2.2) and CMAP after accounting for the diurnal cycle of precipitation. Several other improvements are also included in the present work, which will be discussed in section 3 . The outcome of this study provides 
(a) Precipitation

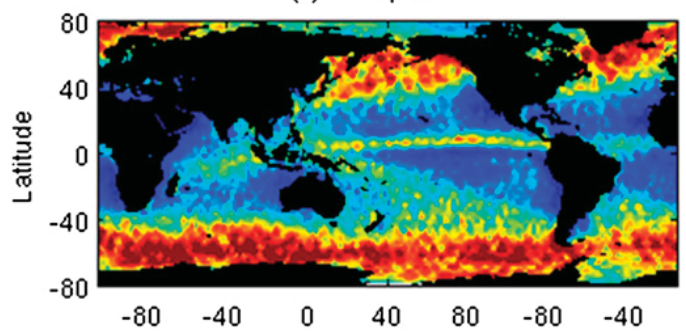

(c) Snow

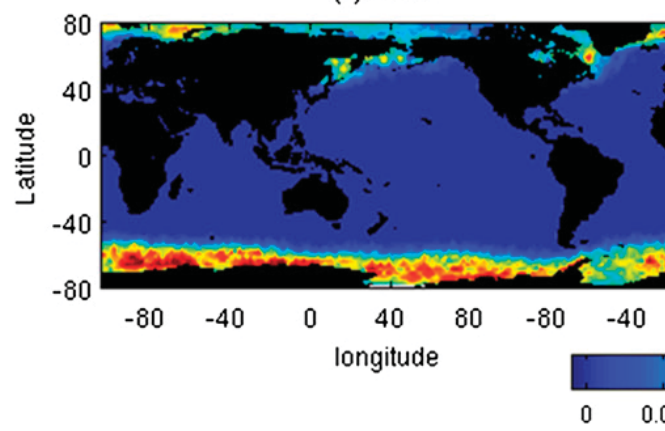

(b) Rain

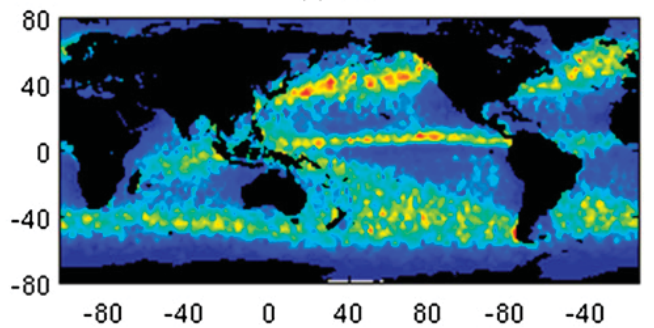

(d) Mixed

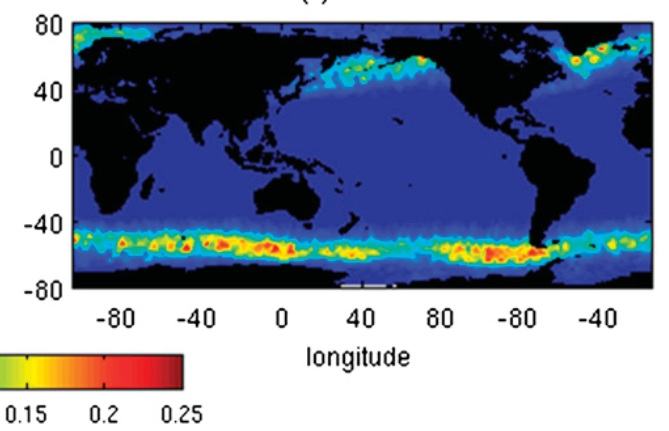

FIG. 1. Precipitation frequency maps over ocean based on CloudSat footprint observations during 2007-09 for (a) total precipitation, (b) rain, (c) snow, and (d) mixed phase.

a new estimate of near-global ocean precipitation rate and its zonal distribution using advanced precipitation measuring sensors and serves as an independent reference to assess precipitation products over the ocean, where due to lack of accurate ground observations evaluation of the climatological absolute magnitude has been problematic (Adler et al. 2012; Tian and PetersLidard 2010).

\section{Data resources}

The following primary datasets from three years (2007-09) of the most recently updated versions are used in this study: (a) CloudSat rain estimate from Release-04 2C-RAIN-PROFILE developed by Mitrescu et al. (2010) and modified by Lebsock and L'Ecuyer (2011), (b) CloudSat snow rate from 2C-SNOWPROFILE (described in http://www.cloudsat.cira.colostate. edu) as well as another product by Liu (2008) that includes the latest modifications based on some recent field comparisons, (c) PR rain rate from the official TRMM PR 2A 25 version 7 products based on the original algorithm developed by Iguchi et al. (2000) together with series of revisions and modifications (Iguchi 2011), (d) the latest version of monthly GPCP precipitation rate (version 2.2; Huffman and Bolvin 2012), and (e) the CMAP product.

The present work also made use of four additional data sources: (a) the TRMM Combined Instrument (TCI) estimate (version 7), which employs data from both TMI and TRMM PR (TRMM product 2B31; Haddad et al. $1997)$; (b) the gridded high resolution $\left(0.25^{\circ} \times 0.25^{\circ}, 3 \mathrm{~h}\right)$ precipitation product from the CPC morphing algorithm (CMORPH; Joyce et al. 2004); (c) precipitation frequency from CloudSat release-04 2C-PRECIPCOLUMN product, developed by Haynes et al. (2009); and (d) Advanced Microwave Scanning Radiometer for Earth Observing System (AMSR-E) rain rate (Wilheit et al. 2003) collocated to CloudSat footprints. The collocated dataset was obtained from the AMSR-E auxiliary product (Release-04) through the data processing center (http://www.cloudsat.cira.colostate.edu).

\section{Methodology and results}

A thorough estimation of the amount and distribution of global precipitation requires the inclusion of both liquid and solid phases of precipitation. Figure 1 shows 2D frequency maps of total oceanic precipitation (Fig. 1a) and rain (Fig. 1b), snow (Fig. 1c), and mixed phase (Fig. 1d) between $80^{\circ} \mathrm{S}$ and $80^{\circ} \mathrm{N}$ obtained from the CloudSat 2C-PRECIP-COLUMN product (Haynes et al. 2009). Mean zonal distribution of precipitation frequencies is also shown in Fig. 2. The $94-\mathrm{GHz}$ (W band) Cloud Profiling Radar (CPR) aboard CloudSat (Stephens et al. 2008), with a minimum detectable signal of $\sim-28 \mathrm{dBZ}$, has provided an unprecedented opportunity to measure snow, drizzle, and light rainfall that goes undetected by other sensors (Behrangi et al. 2012). The zonal distribution of precipitation is not symmetric, and in both 


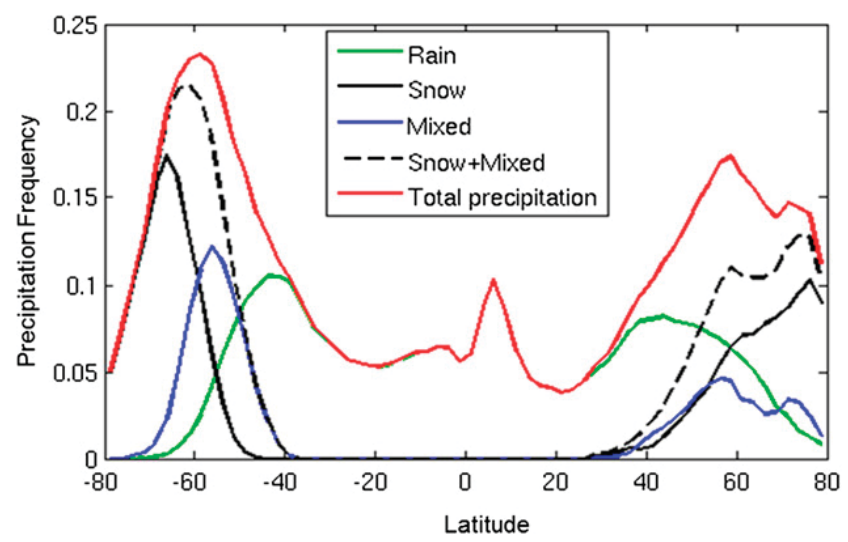

FIG. 2. Zonal distribution of precipitation phase frequencies based on CloudSat footprint observations for 2007-09.

hemispheres, poleward of $\sim 55^{\circ}$ latitude, the solid phase of precipitation gradually becomes dominant (Fig. 2). At $\sim 60^{\circ} \mathrm{S}$, where the precipitation frequency is the largest (more than $23 \%$ ), only about $11 \%$ of all precipitation events occur in the form of rain. This implies that for the estimation of global precipitation, it is important to be able to distinguish between precipitation phases. This is a challenging task given that currently the orbital precipitation products used in GPCP and CMAP do not directly capture solid-phase precipitation intensities. In GPCP snow rate is estimated indirectly using regression relationship between a few collocated rain gauge measurements and cloudrelated parameters from infrared sounders, and CMAP accounts for snowfall only implicitly. In this paper global precipitation rate is calculated through the steps described below.

\section{a. Rain rate estimation}

Among the satellite sensors the 94-GHz (W band) CPR offers the highest sensitivity to capture the occurrence and intensity of drizzle, light rain, and snowfall. On the other hand, the 13.8-GHz PR captures moderate and intense rainfall over tropics, but due to its minimum detectable signal of about $17 \mathrm{dBZ}$ it has a limited sensitivity to detect and estimate light rainfall. The latest version of the CloudSat rainfall product, 2C-RAINPROFILE, uses the path-integrated attenuation in addition to the observed reflectivity profile while implementing relatively more realistic assumptions regarding the vertical distribution of rainwater and the rainfall drop size distribution compared the previous algorithm. This makes the 2C-RAIN-PROFILE product more appropriate for the retrieval of warm rainfall (Lebsock and L'Ecuyer 2011).

By recognizing the complementary information of the two sensors, a merged distribution of rain volume was constructed from the rain volume distribution of CloudSat and PR. The rain volume distribution is a plot of rain intensity versus normalized rain volume within each intensity bin, so that the area below the distribution is unity [see Fig. 9 of Behrangi et al. (2012) for a detailed description of the merging process]. In brief, the merging process comprises three steps. 1) The rain volume distribution is created from CloudSat and PR estimates. 2) The CloudSat rain intensities less than $1 \mathrm{~mm} \mathrm{~h}^{-1}$ and PR rain intensities greater than $1 \mathrm{~mm} \mathrm{~h}^{-1}$ are trusted and used to merge the two rain volume distributions. 3) A constraint is set, so the frequency of rain incidences from the merged PR and CloudSat distribution does not exceed the total count of CloudSat rain incidences. Prior to the count of CloudSat rain incidences, rain rates from five neighboring CPR footprints were averaged to account for the differences in footprint size of PR and CPR as discussed in Behrangi et al. (2012). That study also shows that the effect of the CPR averaging scale is almost negligible when matching to the PR footprint size. In the extratropics, where TRMM PR is not available, precipitation retrievals from Aqua's AMSR-E can significantly underestimate light rainfall and snow compared to that estimated from CloudSat (Behrangi et al. 2012). Conversely, in this region up to about $5 \%$ of rain events captured by CloudSat face a signal saturation problem under the heaviest rainfall (Stephens et al. 2008). Although it is possible to make adjustments to account for these heavy rainfall cases (Tanelli et al. 2008), we chose to use collocated AMSR-E rain rates that include extratropical intense rainfall in the calculations. CloudSat CPR and AMSR-E fly in formation as part of the A-Train, which makes it relatively simple to match up the observations.

\section{b. Snow rate estimation}

The emergence of high-frequency radar on CloudSat with a minimum detectable signal of $\sim-28 \mathrm{dBZ}$ created an excellent opportunity to advance high-latitude precipitation studies. Liu (2008) developed an algorithm (the algorithm is hereafter referred to as Liu08) to estimate snowfall rate from CloudSat measurements. In brief, Liu08 implements a two-step process to retrieve snow rate from CloudSat: 1) distinguishing between liquid and solid phase of precipitation based on ground measurements and weather reports and by identifying a temperature threshold based on conditional probability of solid precipitation as a function of surface air temperature, and 2) converting radar reflectivity to snowfall rate based on backscatter computations of nonspherical ice particles and in situ measured particle distributions. The original rain-snow separation temperature was modified later $\left(1^{\circ} \mathrm{C}\right.$ instead 
of $2^{\circ} \mathrm{C}$ ) as a result of some recent field measurements [G. Liu (the algorithm developer) 2013, personal communication]. Note that while many factors contribute to the uncertainties in snowfall retrieval rates (Hiley et al. 2011), the uncertainty in knowing the snow particle shape and size distribution is a major source of random error for the reflectivity-snowfall rate relation, which could be about $50 \%$ (Liu 2008). A more recent snowfall rate product, 2C-SNOW-PROFILE, is also considered in our calculations. 2C-SNOW-PROFILE retrieves profile of snowfall rate through multiple steps. It first uses the $2 \mathrm{C}$ PRECIP-COLUMN product to identify snowfall and then uses reflectivity and cloud mask and temperature profiles to locate snow layers. An optimal estimation algorithm is used to retrieve profiles of size distribution parameters using a priori information about snow microphysical properties, radar scattering properties, and size distribution parameters. Profiles of snowfall rates and snow water contents are then computed using the retrieved size distribution parameter profiles and the a priori information. The surface snowfall rate is obtained from estimated snow properties in the bottommost portion of the retrieved snow rate profile (a full description of the retrieval algorithm can be obtained from http:// www.cloudsat.cira.colostate.edu). The total precipitation was calculated by adding CloudSat snow rate (form the latest update of the algorithm) to the merged CloudSatTRMM rainfall rate.

\section{c. Accounting for diurnal cycle of precipitation}

The merged CloudSat-TRMM precipitation product provides an estimate of mean precipitation rate at CloudSat equator crossing times ( 01:30 and 13:30 LT). While it is known that the diurnal cycle of mean precipitation rate is not strong over ocean, for a thorough daily estimate one should consider the effect of diurnal cycle of precipitation. Therefore, the diurnal cycle of precipitation was calculated for each $10^{\circ}$ latitudinal band from $55^{\circ} \mathrm{S}$ to $55^{\circ} \mathrm{N}$ and the ratios of daily mean precipitation to mean precipitation at CloudSat equatorcrossing times were calculated. The ratios were then used as adjustment factors to convert mean precipitation rate at the CloudSat equator-crossing times to a daily mean rate. Poleward of $55^{\circ}$ latitude in both hemispheres, no diurnal cycle adjustment was computed because of the lack of reliable subdaily precipitation retrievals. The adjustment factors were calculated using two products: 1) TRMM 2B31 (Haddad et al. 1997) precipitation rate between $38^{\circ} \mathrm{S}$ and $38^{\circ} \mathrm{N}$ because TRMM flies in a sun nonsynchronous orbit and $2 \mathrm{~B} 31$ has been recognized as a high-quality product (Huffman et al. 2007), and 2) $\mathrm{CMORPH}$ for the latitude band $40^{\circ}-55^{\circ}$ in both hemispheres, mainly because CMORPH exclusively uses

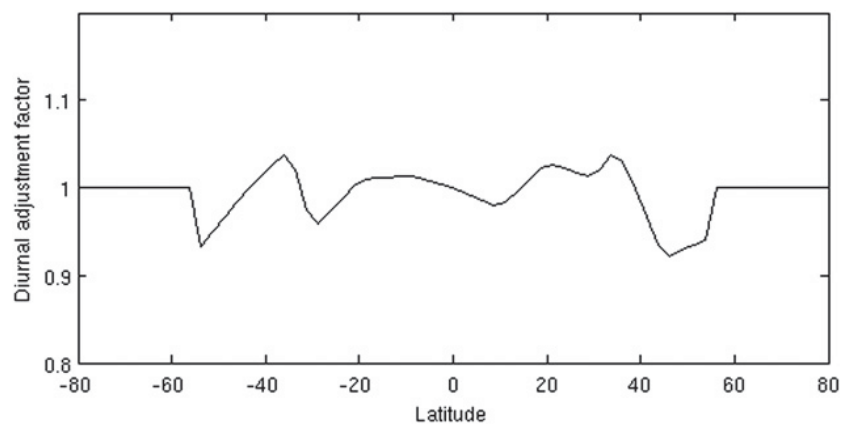

FIG. 3. Diurnal adjustment factor to convert mean precipitation rate at CloudSat equator-crossing times to daily rate.

microwave-based precipitation estimates, and precipitation estimates from microwave sensors are considered more skillful than IR-based products (Adler et al. 2001; Ebert et al. 2007; Behrangi et al. 2009, 2010), especially at high latitudes where convective clouds are less frequent. Figure 3 shows that the adjustment factors are fairly close to unity across all latitudes. Therefore, even without any adjustment, the precipitation rate at CloudSat equatorcrossing times provides a good approximation for daily mean precipitation over ocean. Poleward of $60^{\circ} \mathrm{S} / \mathrm{N}$, where CMORPH does not provide precipitation estimates, no adjustment is considered.

\section{d. Zonal distribution of precipitation and comparison with GPCP}

Zonal distributions of 3-yr (2007-09) mean precipitation rates from MCTA (hereafter MCTA refers to the merged precipitation estimate from the CloudSat, TRMM, and Aqua platforms) with snow rate from 2CSNOW-PROFILE, and the latest versions of GPCP (V2.2) and CMAP are shown in Fig. 4a. Rain-only rates are also shown to distinguish the contribution of snowfall at high latitudes. In addition, by subtracting MCTA precipitation rates from those of GPCP and CMAP, zonal differences (ZD) between GPCP and MCTA and CMAP and MCTA are displayed in Fig. 4b. Relative differences (RD) between the two products and MCTA were calculated by dividing the ZD of each pair by their mean in each $2.5^{\circ}$ zonal bin (Fig. 4c). Compared to MCTA, GPCP and CMAP show large zonal differences in estimating mean precipitation rate (e.g., exceeding $1 \mathrm{~mm} \mathrm{day}^{-1}$ ) in certain zones. In the tropics (between $36^{\circ} \mathrm{S}$ and $36^{\circ} \mathrm{N}$ ) the difference between MCTA and GPCP is the smallest and the observed underestimation of GPCP compared to MCTA is likely caused by missing light precipitation in marine subsidence regions (e.g., Behrangi et al. 2012; Rapp et al. 2013). CMAP displays larger mean precipitation intensity in the intertropical convergence zone (ITCZ) compared to both GPCP and 


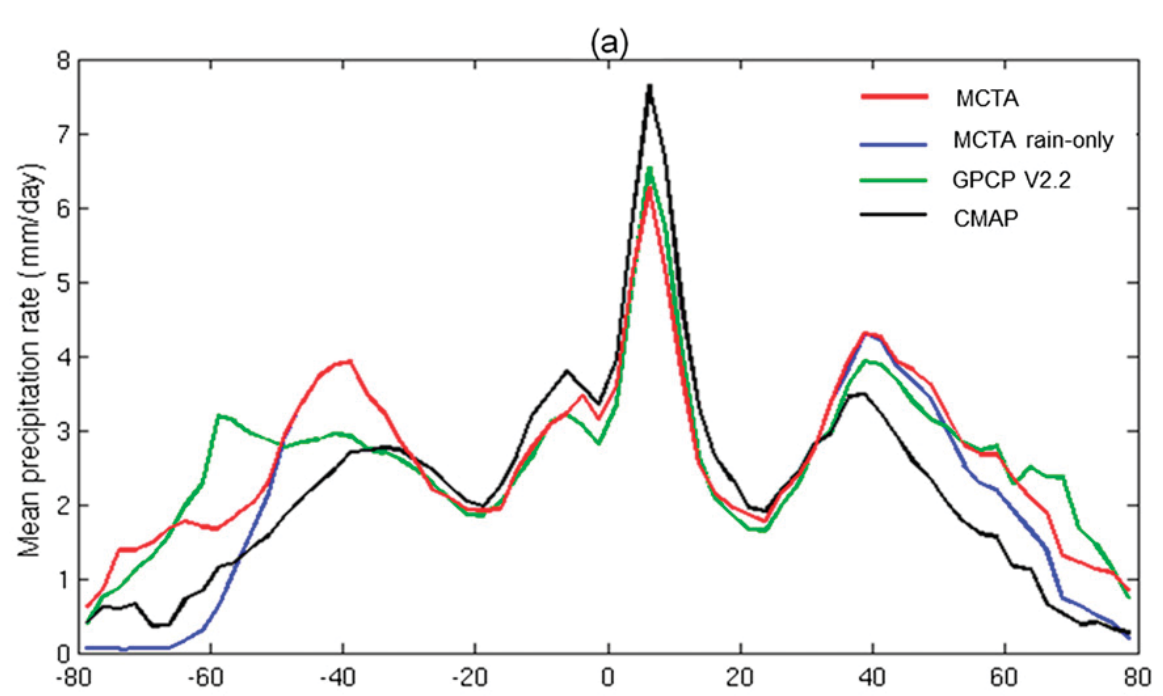

(b)

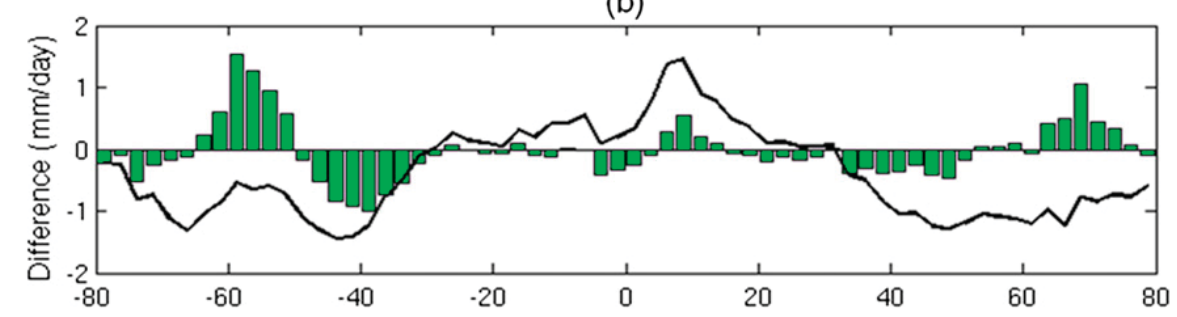

(c)

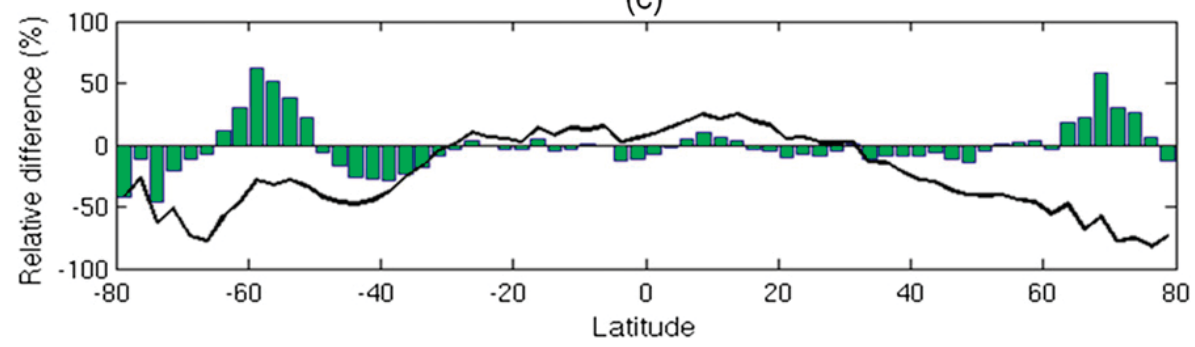

FIG. 4. Zonal distribution of mean precipitation rates and differences compared to the merged CloudSat-TRMM-Aqua precipitation (MCTA) estimate. (a) Mean precipitation rate from the MCTA, GPCP, and CMAP. (b) Zonal difference between GPCP and MCTA (shown with green bars) and CMAP and MCTA (shown with a solid black line). (c) As in (b), but for zonal relative differences calculated by dividing the zonal precipitation differences of each pair by their means. Calculations were performed for each $2.5^{\circ}$ zonal bin.

MCTA. Clearly, the agreement among the products is degraded over higher latitudes, especially over the southern oceans.

Significant differences between the products exist between $30^{\circ}$ and $65^{\circ} \mathrm{S}$ (Fig. 4a). This is important for both water and energy cycle studies as each $1 \mathrm{~mm} \mathrm{day}^{-1}$ of precipitation is equivalent to $\sim 29 \mathrm{~W} \mathrm{~m}^{-2}$ energy through latent heat release. The distinct local maximum precipitation around $40^{\circ} \mathrm{S}$ shown by MCTA is not captured by either GPCP or CMAP. Compared to MCTA, GPCP underestimates the mean zonal precipitation rate between $\sim 30^{\circ} \mathrm{S}$ and $\sim 55^{\circ} \mathrm{S}$, but overestimates it between $55^{\circ}$ and $65^{\circ} \mathrm{S}$. The local maximum around $60^{\circ} \mathrm{S}$ is likely unrealistic. Comparing curves in Fig. 4 around $40^{\circ}$, which is the edge of IR coverage in the GPCP, there is no obvious jump at $40^{\circ}$, so the difference appears related to the microwave algorithm used (microwave emission brightness temperature histograms; Chiu and Chokngamwong 2010). The disagreement between GPCP and MCTA around $60^{\circ}$ [and higher latitudes in the Northern Hemisphere (NH)] is driven by the TOVS/AIRS estimates (Adler et al. 2003). The TOVS/AIRS precipitation algorithm (Susskind and Pfaendtner 1989; Susskind et al. 1997) depends on regression of cloud volume against daily station data, with smoothing functions applied to obtain seasonally and latitudinally varying coefficients. The cloud volume-precipitation relation in the Southern Ocean likely suffers from a lack of local data and is 
TABLE 1. Summary of mean precipitation rate from MCTA and comparison with GPCP V2.2 and CMAP.

\begin{tabular}{|c|c|c|c|c|c|c|}
\hline & & $80^{\circ} \mathrm{S}-80^{\circ} \mathrm{N}$ & $80^{\circ} \mathrm{S}-0^{\circ}$ & $0^{\circ}-80^{\circ} \mathrm{N}$ & $60^{\circ} \mathrm{S}-60^{\circ} \mathrm{N}$ & $36^{\circ} \mathrm{S}-36^{\circ} \mathrm{N}$ \\
\hline \multirow[t]{2}{*}{ Present study } & $\operatorname{MCTA}\left(\mathrm{mm} \mathrm{day}^{-1}\right)$ & 2.94 & 2.65 & 3.24 & 3.13 & 3.02 \\
\hline & Rain only (mm day ${ }^{-1}$ ) & 2.77 & 2.43 & 3.12 & 3.07 & 3.02 \\
\hline \multirow[t]{3}{*}{ GPCP } & GPCP V2.2 (mm day $\left.{ }^{-1}\right)$ & 2.82 & 2.51 & 3.13 & 2.97 & 2.90 \\
\hline & GPCP-MCTA $\left(\mathrm{mm} \mathrm{day}^{-1}\right)$ & -0.12 & -0.14 & -0.11 & -0.16 & -0.12 \\
\hline & GPCP relative difference ( $\%)$ & -4.17 & -5.43 & -3.45 & -5.25 & -4.05 \\
\hline \multirow[t]{3}{*}{ CMAP } & CMAP $\left(\mathrm{mm} \mathrm{day}^{-1}\right)$ & 2.68 & 2.32 & 3.04 & 2.96 & 3.28 \\
\hline & CMAP-MCTA $\left(\mathrm{mm} \mathrm{day}^{-1}\right)$ & -0.26 & -0.33 & -0.20 & -0.17 & 0.26 \\
\hline & CMAP relative difference $(\%)$ & -9.25 & -13.28 & -6.37 & -5.58 & 8.25 \\
\hline
\end{tabular}

strongly influenced by the smoothing process. CMAP displays a lower mean precipitation rate compared to MCTA poleward of latitude $30^{\circ}$ in both hemispheres. This could be related to the common underestimation of precipitation by individual microwave- and infraredbased products used in the generation of CMAP. Note that poleward of approximately $60^{\circ} \mathrm{S}$ one can see that precipitation is almost completely snow, whereas in the $\mathrm{NH}$ a significant portion of the total precipitation is still rain as can be inferred from comparison of MCTA and MCTA rain-only in Fig. 4a (also see Fig. 2). The presence of more snowfall in the Southern Hemisphere (SH) and the inability of current level-2 precipitation products to directly observe snowfall makes it potentially more difficult to estimate accurate precipitation rates in this zone.

The differences are less significant when precipitation rates are averaged globally or within a large zone (Table 1 ). The near-global $\left(80^{\circ} \mathrm{S}-80^{\circ} \mathrm{N}\right)$ mean oceanic precipitation rate from MCTA is $\sim 2.94 \mathrm{~mm} \mathrm{day}^{-1}$, which is about $4.17 \%$ ( $0.12 \mathrm{~mm}$ day $\left.^{-1}\right)$ higher than that estimated by GPCP (2.82 $\left.\mathrm{mm} \mathrm{day}^{-1}\right)$ and about 9.25\% (0.26 $\left.\mathrm{mm} \mathrm{day}^{-1}\right)$ higher than that obtained from CMAP $\left(2.68 \mathrm{~mm} \mathrm{day}^{-1}\right)$. For GPCP, the calculated relative differences are within the recent bias error estimate of about $7 \%$ (9\%) for climatological precipitation over tropical (global) oceans (Adler et al. 2012).

Based on the 2C-SNOW-PROFILE product, the contribution of snowfall to the near-global oceanic precipitation rate is about $0.17 \mathrm{~mm} \mathrm{day}^{-1}(\sim 5.8 \%$ of total precipitation; see Table 1). The MCTA estimate of mean precipitation rate (rain plus snow) in the $\mathrm{NH}$ is about $3.24 \mathrm{~mm} \mathrm{day}^{-1}$, with snowfall contributing about $0.12 \mathrm{~mm} \mathrm{day}^{-1}(\sim 3.7 \%$ of total precipitation). In the $\mathrm{SH}$, the mean precipitation rate from MCTA is $2.65 \mathrm{~mm}^{\text {day }}{ }^{-1}$. In both hemispheres the MCTA estimate is higher than GPCP's or CMAP's. Snowfall in the SH is $\sim 0.22 \mathrm{~mm}^{\text {day }}{ }^{-1}$ ( $\sim 8.3 \%$ of total precipitation), considerably larger than that in NH. Similar results are obtained using the CloudSat Liu08 snow product, as the two products show high agreement in capturing the zonal mean snowfall rate over ocean (Fig. 5). A maximum difference of about $0.2 \mathrm{~mm} \mathrm{day}^{-1}(\sim 15 \%$ relative difference) is observed at approximately $60^{\circ} \mathrm{S}$. As the two products are independent of each other, it can be inferred that snow retrieval at this zone may have higher uncertainty than other zones.

\section{Conclusions and final remarks}

The more precise knowledge of precipitation amount and distribution improves our understanding of the current state of Earth's climate and the water and energy budgets and how the hydrological cycle responds to the zonal energy imbalances that force climate change (Andrews et al. 2009). Therefore, it enhances our ability to understand how Earth's climate responds to increasing concentrations of greenhouse gases.

Complementary measurements from the CloudSat CPR, TRMM PR, and AMSR-E sensors offer a wide range of sensitivity to drizzle, light rainfall, snowfall, and intense precipitation that is not yet used in current merged precipitation products. Using these three advanced sensors and the merging technique described earlier, our estimate for 3-yr (2007-09) near-global $\left(80^{\circ} \mathrm{S}-80^{\circ} \mathrm{N}\right)$ oceanic

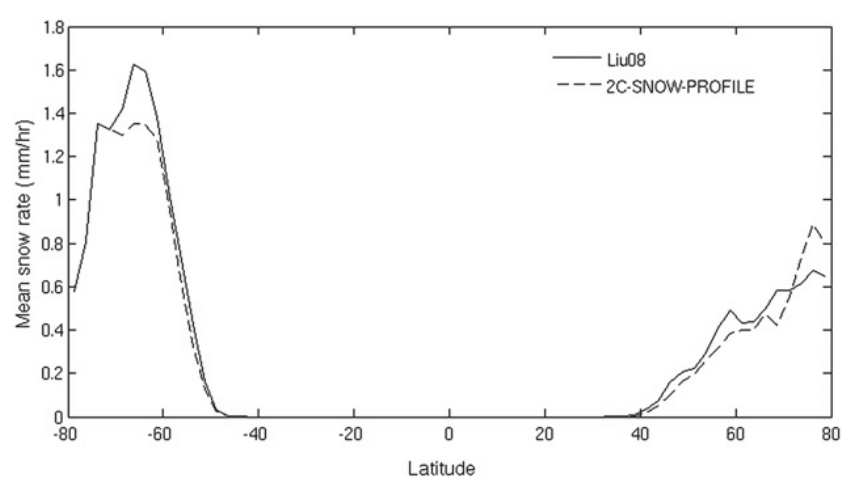

FIG. 5. Comparison of zonal distribution of surface snowfall rate estimated from CloudSat using Liu08 (solid line) and CloudSat 2CSNOW-PROFILE (dashed line) retrievals. The results were generated using approximately $100 \times 10^{6}$ CloudSat samples collected between 2007 and 2009. 
mean precipitation rate is $\sim 2.94 \mathrm{~mm} \mathrm{day}^{-1}$. This new estimate of mean global ocean precipitation is about $9 \%$ higher than that of CMAP $\left(2.68 \mathrm{~mm} \mathrm{day}^{-1}\right)$, mainly due to the lower estimate of CMAP at high latitudes. The MCTA estimate is only about $4 \%$ higher than that of GPCP $\left(2.82 \mathrm{~mm} \mathrm{day}^{-1}\right)$, but not as much as the $\sim 15 \%$ considered recently to bring the surface energy budget into a balance (Stephens et al. 2012). We recognize that the uncertainty in global estimates of precipitation is itself subject to uncertainty, especially at higher latitudes, and is a topic of debate and ongoing research. MCTA, however, suggests distinct differences in the zonal distribution of precipitation rate from that depicted in GPCP and CMAP, especially in the SH. Such zonal differences go beyond the known uncertainties and may exceed $1 \mathrm{~mm}^{-1 a y}{ }^{-1}$ (or $\sim 29 \mathrm{~W} \mathrm{~m}^{-2}$ energy through latent heat release) in certain zones, especially at higher latitudes. However, the differences tend to cancel if precipitation is averaged over large portions of the globe.

Precipitation estimation at higher latitudes is clearly a major challenge that has not been fully addressed by the Earth observing community. While substantial surface observation of oceanic precipitation will remain impractical, our new estimate using the latest advances in remote sensing of precipitation can set a guideline for revising current climate data records of precipitation, surface energy balance, and evaluation of reanalyses and climate models. The upcoming Global Precipitation Measurement (GPM; Hou et al. 2008) mission will extend the joint radar/passive microwave radiometer capability pioneered by TRMM to retrieve precipitation of all phases to a latitude range of $65^{\circ} \mathrm{N}$ to $65^{\circ} \mathrm{S}$, with significant improvements expected over land, and the future EarthCARE mission (Bezy et al. 2005) will extend CloudSat-like observations. Efforts are underway to create seasonal climatology maps of oceanic precipitation from MCTA, provide uncertainty data, and include the most recent datasets for the latest update. Furthermore, the authors are planning to explore available ground validation resources including oceanic shipboard precipitation datasets (Petty 1997; Ellis et al. 2009; Andersson et al. 2011) and other sources such as atoll data and buoys for further evaluation and refinement of the results. This work is also invaluable to improve future generation of the global precipitation climatology products.

Acknowledgments. The research described in this paper was carried out at the Jet Propulsion Laboratory, California Institute of Technology, under a contract with the National Aeronautics and Space Administration. Government sponsorship is acknowledged.

\section{REFERENCES}

Adler, R. F., C. Kidd, G. Petty, M. Morissey, and H. M. Goodman, 2001: Intercomparison of global precipitation products: The third Precipitation Intercomparison Project (PIP-3). Bull. Amer. Meteor. Soc., 82, 1377-1396, doi:10.1175/1520-0477(2001)082<1377: IOGPPT $>2.3 . \mathrm{CO} ; 2$.

— , and Coauthors, 2003: The version-2 Global Precipitation Climatology Project (GPCP) monthly precipitation analysis (1979-present). J. Hydrometeor., 4, 1147-1167, doi:10.1175/ 1525-7541(2003)004<1147:TVGPCP > 2.0.CO;2.

— , G. Gu, and G. J. Huffman, 2012: Estimating climatological bias errors for the Global Precipitation Climatology Project (GPCP). J. Appl. Meteor. Climatol., 51, 84-99, doi:10.1175/ JAMC-D-11-052.1.

Andersson, A., C. Klepp, K. Fennig, S. Bakan, H. Grassl, and J. Schulz, 2011: Evaluation of HOAPS-3 ocean surface freshwater flux components. J. Appl. Meteor. Climatol., 50, 379-398, doi:10.1175/2010JAMC2341.1.

Andrews, T., P. M. Forster, and J. M. Gregory, 2009: A surface energy perspective on climate change. J. Climate, 22, 25572570, doi:10.1175/2008JCLI2759.1.

Behrangi, A., K.-L. Hsu, B. Imam, S. Sorooshian, G. J. Huffman, and R. J. Kuligowski, 2009: PERSIANN-MSA: A precipitation estimation method from satellite-based multispectral analysis. J. Hydrometeor., 10, 1414-1429, doi:10.1175/2009JHM1139.1.

—, B. Imam, K.-L. Hsu, S. Sorooshian, T. J. Bellerby, and G. J. Huffman, 2010: REFAME: Rain Estimation Using ForwardAdjusted Advection of Microwave Estimates. J. Hydrometeor., 11, 1305-1321, doi:10.1175/2010JHM1248.1.

— M. Lebsock, S. Wong, and B. Lambrigtsen, 2012: On the quantification of oceanic rainfall using spaceborne sensors. J. Geophys. Res., 117, D20105, doi:10.1029/2012JD017979.

Berg, W., T. L'Ecuyer, and J. M. Haynes, 2010: The distribution of rainfall over oceans from spaceborne radars. J. Appl. Meteor. Climatol., 49, 535-543, doi:10.1175/2009JAMC2330.1.

Bezy, J.-L., W. Leibrandt, A. Heliere, P. Silvestrin, C.-C. Lin, P. Ingmann, T. Kimura, and H. Kumagai, 2005: The ESA Earth Explorer EarthCARE mission. Earth Observing Systems $X$, J. J. Butler, Ed., International Society for Optical Engineering (SPIE Proceedings, Vol. 5882), 143-154.

Bolvin, D. T., R. F. Adler, G. J. Huffman, E. J. Nelkin, and J. P. Poutiainen, 2009: Comparison of GPCP monthly and daily precipitation estimates with high-latitude gauge observations. J. Appl. Meteor. Climatol., 48, 1843-1857, doi:10.1175/ 2009JAMC2147.1.

Chiu, L. S., and R. Chokngamwong, 2010: Microwave emission brightness temperature histograms (METH) rain rates for climate studies: Remote Sensing Systems SSM/I version-6 results. J. Appl. Meteor. Climatol., 49, 115-123, doi:10.1175/ 2009JAMC2204.1.

Ebert, E. E., J. E. Janowiak, and C. Kidd, 2007: Comparison of near-real-time precipitation estimates from satellite observations and numerical models. Bull. Amer. Meteor. Soc., 88, 4764, doi:10.1175/BAMS-88-1-47.

Ellis, T. D., T. L'Ecuyer, J. M. Haynes, and G. L. Stephens, 2009: How often does it rain over the global oceans? The perspective from CloudSat. Geophys. Res. Lett., 36, L03815, doi:10.1029/2008GL036728.

Haddad, Z. S., E. A. Smith, C. D. Kummerow, T. Iguchi, M. R. Farrar, S. L. Durden, M. Alves, and W. S. Olson, 1997: The TRMM 'day-1' radar/radiometer combined rain-profiling algorithm. J. Meteor. Soc. Japan, 75, 799-809. 
Haynes, J. M., T. S. L'Ecuyer, G. L. Stephens, S. D. Miller, C. Mitrescu, N. B. Wood, and S. Tanelli, 2009: Rainfall retrieval over the ocean with spaceborne W-band radar. J. Geophys. Res., 114, D00A22, doi:10.1029/2008JD009973.

Hiley, M. J., M. S. Kulie, and R. Bennartz, 2011: Uncertainty analysis for CloudSat snowfall retrievals. J. Appl. Meteor. Climatol., 50, 399-418, doi:10.1175/2010JAMC2505.1.

Hou, A. Y., G. Skofronick-Jackson, C. Kummerow, and M. Shepherd, 2008: Global measurement. Precipitation: Advances in Measurement, Estimation and Prediction, S. Michaelides, Ed., Springer Verlag, 131-164.

Huffman, G. J., and D. T. Bolvin, 2012: GPCP version 2.2 SG combined precipitation data set documentation. $46 \mathrm{pp}$. [Available online at ftp://precip.gsfc.nasa.gov/pub/gpcp-v2.2/ doc/V2.2_doc.pdf.]

, R. F. Adler, M. M. Morrissey, D. T. Bolvin, S. Curtis, R. Joyce, B. McGavock, and J. Susskind, 2001: Global precipitation at one-degree daily resolution from multisatellite observations. J. Hydrometeor., 2, 36-50, doi:10.1175/15257541(2001)002<0036:GPAODD>2.0.CO;2.

—_, and Coauthors, 2007: The TRMM multisatellite precipitation analysis (TMPA): Quasi-global, multiyear, combined-sensor precipitation estimates at fine scales. J. Hydrometeor., 8, 3855, doi:10.1175/JHM560.1.

— R. F. Adler, D. T. Bolvin, and G. Gu, 2009: Improving the global precipitation record: GPCP version 2.1. Geophys. Res. Lett., 36, L17808, doi:10.1029/2009GL040000.

Iguchi, T., 2011: Evolution of the rain profiling algorithm for the TRMM Precipitation Radar. Proc. 2011 IEEE Int Geoscience and Remote Sensing Symp. (IGARSS 2011), Vancouver, BC, Canada, IEEE, 1562-1564, doi:10.1109/ IGARSS.2011.6049368.

- , T. Kozu, R. Meneghini, J. Awaka, and K. I. Okamoto, 2000: Rain-profiling algorithm for the TRMM Precipitation Radar. J. Appl. Meteor., 39, 2038-2052, doi:10.1175/ 1520-0450(2001)040<2038:RPAFTT >2.0.CO;2.

Joyce, R. J., J. E. Janowiak, P. A. Arkin, and P. Xie, 2004: CMORPH: A method that produces global precipitation estimates from passive microwave and infrared data at high spatial and temporal resolution. J. Hydrometeor., 5, 487-503, doi:10.1175/1525-7541(2004)005<0487:CAMTPG > 2.0.CO;2.

Kiehl, J. T., and K. E. Trenberth, 1997: Earth's annual global mean energy budget. Bull. Amer. Meteor. Soc., 78, 197-208, doi:10.1175/1520-0477(1997)078<0197:EAGMEB>2.0.CO;2.

Lebsock, M. D., and T. S. L'Ecuyer, 2011: The retrieval of warm rain from CloudSat. J. Geophys. Res., 116, D20209, doi:10.1029/ 2011JD016076.

Liu, G., 2008: Deriving snow cloud characteristics from CloudSat observations. J. Geophys. Res., 113, D00A09, doi:10.1029/ 2007JD009766.

Mitrescu, C., T. L'Ecuyer, J. Haynes, S. Miller, and J. Turk, 2010: CloudSat precipitation profiling algorithm-Model description. J. Appl. Meteor. Climatol., 49, 991-1003, doi:10.1175/ 2009JAMC2181.1.

Petty, G. W., 1997: An intercomparison of oceanic precipitation frequencies from 10 Special Sensor Microwave/Imager rain rate algorithms and shipboard present weather reports. J. Geophys. Res., 102, 1757-1777, doi:10.1029/96JD03000.

Rapp, A., M. Lebsock, and T. L'Ecuyer, 2013: Low cloud precipitation climatology in the southeastern Pacific marine stratocumulus region using CloudSat. Environ. Res. Lett., 8, 014027, doi:10.1088/1748-9326/8/1/014027.

Stephens, G. L., and Coauthors, 2008: CloudSat mission: Performance and early science after the first year of operation. J. Geophys. Res., 113, D00A18, doi:10.1029/2008JD009982.

and Coauthors, 2010: Dreary state of precipitation in global models. J. Geophys. Res., 115, D24211, doi:10.1029/ 2010JD014532.

-, and Coauthors, 2012: An update on Earth's energy balance in light of the latest global observations. Nat. Geosci., 5, 691-696, doi:10.1038/ngeo1580.

Susskind, J., and J. Pfaendtner, 1989: Impact of interactive physical retrievals on NWP. Report on the Joint ECMWF/EUMETSAT Workshop on the Use of Satellite Data in Operational Weather Prediction: 1989-1993, Vol. 1, T. Hollingsworth, Ed., ECMWF, 245-270

, P. Piraino, L. Rokke, L. Iredell, and A. Mehta, 1997: Characteristics of the TOVS Pathfinder Path A dataset. Bull. Amer. Meteor. Soc., 78, 1449-1472, doi:10.1175/ 1520-0477(1997)078<1449:COTTPP>2.0.CO;2.

Tanelli, S., S. L. Durden, E. Im, K. S. Pak, D. G. Reinke, P. Partain, J. M. Haynes, and R. T. Marchand, 2008: CloudSat's cloud profiling radar after two years in orbit: Performance, calibration, and processing. IEEE Trans. Geosci. Remote Sens., 46, 3560-3573, doi:10.1109/TGRS.2008.2002030.

Tian, Y., and C. D. Peters-Lidard, 2010: A global map of uncertainties in satellite-based precipitation measurements. Geophys. Res. Lett., 37, L24407, doi:10.1029/2010GL046008.

Trenberth, K. E., L. Smith, T. T. Qian, A. Dai, and J. Fasullo, 2007: Estimates of the global water budget and its annual cycle using observational and model data. J. Hydrometeor., 8, 758-769, doi:10.1175/JHM600.1.

—_ J. T. Fasullo, and J. Kiehl, 2009: Earth's global energy budget. Bull. Amer. Meteor. Soc., 90, 311-323, doi:10.1175/ 2008BAMS2634.1.

Wilheit, T., C. D. Kummerow, and R. Ferraro, 2003: NASDA rainfall algorithms for AMSR-E. IEEE Trans. Geosci. Remote Sens., 41, 204-214, doi:10.1109/TGRS.2002.808312.

Wong, S., T. S. L'Ecuyer, W. S. Olson, X. Jiang, and E. J. Fetzer, 2014: Local balance and variability of atmospheric heat budget over oceans: Observation and reanalysis-based estimates. J. Climate, 27, 893-913, doi:10.1175/JCLI-D-13-00143.1.

Xie, P., and P. A. Arkin, 1997: Global precipitation: A 17-year monthly analysis based on gauge observations, satellite estimates, and numerical model outputs. Bull. Amer. Meteor. Soc., 78, 2539-2558, doi:10.1175/1520-0477(1997)078<2539: GPAYMA $>2.0 . \mathrm{CO} ; 2$.

- J. E. Janowiak, P. A. Arkin, R. Adler, A. Gruber, R. Ferraro, G. J. Huffman, and S. Curtis, 2003: GPCP pentad precipitation analyses: An experimental dataset based on gauge observations and satellite estimates. J. Climate, 16, 2197-2214, doi:10.1175/2769.1. 